\title{
MPL NP_005364.1:p.W515K
}

National Cancer Institute

\section{Source}

National Cancer Institute. MPL NP 005364.1:p.W515K. NCI Thesaurus. Code C126825.

A change in the amino acid residue at position 515 in the thrombopoietin receptor protein where tryptophan has been replaced by lysine. 